\title{
Refugee Students in Toronto Schools
}

\author{
Maria Yau, Toronto Board of Education
}

\begin{abstract}
This is an abridged version of a full report entitled Refugee Students in Toronto Schools: An Exploratory Study. The report, which was released by the Toronto Board of Education in 1995, (1) discusses the situation of refugee students in Toronto schools, (2) examines how school staff dealt with the change in student population and the challenges they faced, and (3) suggests ways to help teachers, schools and the school system meet the needs of the newly arrived refugee students. While this article captures most of the major findings of the study, a considerable amount of details contained in the full report-for example, some of the statistics, case studies, anecdotes collected from refugee students and parents, and specific programs and suggestions-are omitted in order to accommodate the length requirement of this publication. Readers who are interested in the detailed study can contact the Research and Assessment Department of the Toronto Board of Education.
\end{abstract}

\section{Précis}

Ceci est la version abrégée d'un rapport intitulé: Les Étudiants réfugiés dans les écoles de Toronto: une Étude exploratoire. Ce rapport, émis par le Conseil de l'Éducation de Toronto en 1995, (1) décrit la situation des étudiants réfugiés dans les écoles torontoises (2) examine la façon dont le personnel des institutions scolaires s'adapte aux changements de la population estudiantine et aux défis qu'ils représentent, et (3) formule des propositions visant à aider les enseignants, les écoles et l'administration scolaire a mieux rencontrer les besoins spécifiques des étudiants réfugiés nouvellement arrivés. Cet article synthétise les principaux éléments $d$ 'information figurant dans l'étude en

Maria Yau is a Research Officer with the Toronto Board of Education, Toronto. question. Cependant vu les contraintes d'espace de la présente publication, un grand nombre de détails figurant dans le rapport complet sont omis ici - on pense notamment à un certain nombre $d$ 'informations statistiques, $d$ 'études de cas, d'anecdotes colligées auprès d'étudiants et de parents, ainsi qu'à la description de certains programmes et d certaines suggestions spécifiques. Le lecteur intéresséà prendre connaissance de l'étude dans son entier est prié de contacterle Bureau de la Recherche et de $l^{\prime}$ Évaluation du Conseil de l'Éducation de Toronto.

$\mathrm{T}$ The late 1980 s and early 1990 s witnessed a rapid growth of the refugee population in Toronto. It was estimated that in late 1991 the Toronto School Board had roughly 5,500 refugee students coming from nine major source countries; three years later, due to the rising number of refugee producing countries, especially those from Eastern Europe, the refugee population in Toronto's schools grew to about 6,900 (an increase of $25 \%$ ).By late 1994, refugee students made up 13 percent (approximately 3,900 students) of the Toronto secondary school population, and 7 percent (approximately 3,000 students) of its elementary school students. ${ }^{1}$

Despite the significant inflow of refugee students, little has been known about them. In 1991, the Guidance and Counselling Department of the Toronto Board of Education asked the Board's Research Department to investigate the refugees' situation in the school system as a whole. An exploratory study was carried out with a threefold objective:

1. to understand the situation of refugee students in Toronto's schoolstheir numbers and distributions, countries of origin, demographic characteristics, family background, migration process, settlement and adjustments, and their challenges and needs at school;

2. to examine how teachers and other school staff deal with the situation, and the kinds of difficulties they have encountered in the process; and

3. to identify ways to help teachers, schools and the school system meet the academic, social and emotional needs of newly arrived refugee students.

In addition to existing literature and statistics, first-hand information was collected through :

- individual interviews with 135 refugee students and 60 refugee parents representing seven different language groups; the interviews were conducted individually by 19 trained interpreters in order to encourage candid discussions with the students and parents;

- a series of focus group interviews with 32 classroom teachers, 14 teachers who taught English as a Second Language, seven school principals as well as representatives from five different student support professional groups; and

- observations of local school team meetings in the seven sampled schools.

In addition, an advisory team was formed with a number of Board members including two researchers, a curriculum superintendent, the chief psychiatrist, a supervisory psychologist, a social worker, guidance counsellors, an English as a Second Language (ESL) co-ordinator, and an ESL consultant.

For the purpose of this study, refugees in this report consisted of three groups of newcomers: refugee claimants, refugee immigrants, and illegal immigrants. Although the definition is broad, it does distinguish these three

Refuge, Vol. 15, No. 5 (1996) 
groups of newcomers from "regular" immigrants who came to this country through formal immigration channels-i.e. having to go through the federal government's point-system screening process, which includes such criteria as physical health and financial status. As discussed below, this distinction is important. While both groups-immigrants and refugees-are new to the country, their premigration, migration, and post-migration experiences as well as their adjustment process are so different that they could hardly be identified as a homogeneous group.

A cursory look at their demographic profiles already shows that refugee students were distinct from those of the immigrant or the local student population. Data extracted from the 1991-92 Toronto Board Secondary Student Survey reveals the following differences.

- While the gender distribution was more or less even among the immigrant and Canadian-born students, the majority $(58 \%)$ of secondaryschool refugee students were male.

- Nearly half $(47 \%)$ of the refugee students were over 19 years of age, as compared to 19 percent among other foreign-born students, and 5 percent among the Canadian-born.

- At least half of the refugee students reported living on their own-a proportion which was more than double that of regular immigrant students (50\% versus $21 \%$ ). And nearly a third $(30 \%)$ of these refugee students who lived on their own were teenagers.

- For those who were with their families, half $(50 \%)$ of the refugee parents were either unemployed or employed in the unskilled, manual labour sector. In fact, the largest proportion of refugee parents were non-remunerative (40\%)-a proportion which was significantly higher than that of the immigrant students $(16 \%)$ and of the Canadian-born (7\%).

The individual interviews with nearly 200 refugee students and parents further demonstrated their unique premigration, migration and post-migration experiences that had a great impact on their school adjustment process.

\section{Premigration and Migration Experiences}

Previous schooling for many refugee students was often disrupted by the premigration situations in their homeland, and by the long and transitory nature of their migration journeys. This was especially so for those who had been confined in refugee camps for an indefinite period of time. Aside from interrupted schooling, the trauma many refugee students went through in their home countries and during their exodus had affected their emotional wellbeing even after settling in a new country. While it is beyond the scope of this report to examine the psychological implications of these students' previous refugee experiences, it is strongly believed that their history and background are crucial factors to bear in mind when one attempts to assess and address the academic, social and emotional needs of refugee students.

\section{Post-migration Experiences}

After their escapes and long migration journeys, refugees did feel safe and hopeful when they finally landed in their destined country. Nevertheless, this sense of relief or gratefulness by no means signified the end of their refugee experience. Rather, it marked the beginning of the third stage of their experience as refugees-i.e. their postmigration or initial resettlement stage. Apart from coping with a whole new language and culture-an experience that all new immigrants have to face and that is never easy even under normal resettlement circumstancesrefugees were confronted with a host of additional barriers which rendered their adjustment process more complicated and difficult than that of regular immigrants. Following is a discussion of obstacles they confronted.

\section{Post-traumatic stress and an on- going sense of fear}

Although the study did not intend to assess Post-Traumatic Stress Disorder, a variety of symptoms were reported. These included sleep problems, nightmares, difficulties concentrating in school, frequent crying, feeling depressed and frequent feelings of fear. Some refugee groups, especially those from Central America, were still fearful of their home government, although they were physically away from the country. The parents were considerably wary, suspicious, and reserved when approached by outsiders, including teachers or our Spanishspeaking interviewers. Often the sense of fear extended beyond their own personal security to apprehension for family members who were still in the home country where conditions remained unsafe or had deteriorated. As noted by a few secondary school teachers, it was hard for these students to get their minds off the bad news from farapart families, and to remain focused on their school work with such lingering thoughts and images.

\section{Precarious residency status and endurance of long bureaucratic processes}

There were many refugee students in our schools who were still undergoing a long bureaucratic process and legal procedures, waiting for hearings or government decision about their status, despite the fact that some had been in the country for three or four years. This was particularly true of those from Somalia and China. These refugees described how worried, insecure and unsettled they were, especially after learning about deportation of other refugees from their own community.

Due to their precarious status, for some, especially "illegal" immigrants, school entry could be delayed for an extended period of time. It is true that public schools are supposed to accept all school-age children regardless of their legal status; but the school registration process could be held back because of the lack of proper immigration papers or official documents. More- 
over, out of their own fear and/or lack of knowledge about the school system, some did not enrol themselves or their children in school without a clear status, or others were afraid to do so in fear of exposing their illegal stay. As a result, it was not uncommon to find school-age refugees staying away from school for a year or up to two years. Regular school attendance could also be a problem for refugee claimant students. A few secondary school teachers noted that some of their refugee students had to be away from school periodically, sometimes up to four or five days, to deal with their residency matters with either their lawyers or immigration officials.

\section{Disintegration of family units}

Only about a third of the refugee students in our secondary schools stayed with both parents, approximately 15 percent were with single parents, and over half were not with any parents at all. The latter either lived by themselves; or in the case of "unaccompanied minors" - stayed with relatives or friends. Without any direct contact with and emotional support from parents and other family members, many refugee students experienced intense loneliness, sadness or helplessness in the new country.

Single parents who were forced to separate from their spouse and family also reported feeling unsettled, sad and lonely without social supports. The new reality was even harder on unaccompanied children. Although many of these young students stayed with their "uncles" or "aunts," the latter were often too preoccupied with their own problems and lives to provide the kind of care and attention that is normally afforded by parents.

\section{Financial difficulties}

Unlike most regular immigrants, most refugees left their countries with few or no possessions, and were virtually penniless when they landed in the host country. Hence, students who came on their own had to either rely on student welfare, or work for long hours to support themselves. Students reported how they had to leave school right after class to work until late in the evening and could only attend to their study at midnight. This might explain why these students often showed signs of fatigue in class, and had neither the time nor the inclination to participate in extracurricular or social activities.

The economic situation was particularly tight for growing or single-parent families. The parents, though working, were emotionally unsettled-worrying about rent and their children's education. Single mothers were either on welfare or earned their living through low-paying jobs and struggled to maintain their accommodations and budgets. Furthermore, many refugee parents experienced downward mobility with a sense of shame and frustration.

Finding affordable housing was also a problem for refugee families. Often the living conditions were substandard and crowded-renting small flats or one/two rooms, or sharing a place with other families which left the children with a lack of space, privacy, or a quiet place to do homework. It was also found that for some refugee students, their family budget was so tight that they could hardly afford any lunch, without the food programs offered by the school. A few elementaryschool students further noted that their family's financial difficulty had precluded them from participating in extracurricular activities. Also, these students rarely had the chance to visit new places with their families, as their parents were often too busy with work, short of disposable incomes, and/or unfamiliar with the new country. This explains why these students were particularly thrilled with the field trips organized by their schools.

\section{Frequent relocations}

Many of the refugee students interviewed, regardless of origin, reported staying temporarily in reception centres, emergency shelters, hostels, settlement houses, or friends/relatives' places for some time upon their arrival, and then moving on to other temporary shelters or new accommodations.
Frequent shifts from school to school made it hard for these students to maintain the continuity in programming and bonding with teachers which are essential for optimal learning.

A few teachers indeed expressed their frustration about working with newly arrived refugee students from nearby hostels or settlement houses only to find a few weeks later that these students had to move, and the teachers had no further knowledge about the students' schooling. Moreover, being often new to a school especially in the middle of a year, these students were vulnerable or susceptible to becoming victims of discrimination, bullying or racial incidents

\section{Cultural disorientation}

Culture shock is common to anyone new to a foreign country. However, the degree of disorientation is likely to be more intense for refugees than for regular immigrants. The latter usually have the time and resources to prepare and adjust themselves both financially and psychologically for their destined country, though orientation and adjustment are still inevitable. Refugees, however, usually had to leave their country in a hurry and were often unsure of their final destination, and some had to adjust to several different cultures and languages within a few years.

Although all the above-mentioned obstacles were not school-related, they had important ramifications on these students' adjustment to their new school lives. For instance, because of their many preoccupations, these students were likely to have a hard time focusing on school work and establishing social relations. Their frustrations at home could even lead to inappropriate and violent behaviours at school. Therefore, before one could really appreciate the school needs of refugee students (which are more than the need for ESL development), it is important to have some knowledge of the past and present circumstances these students have gone through outside school. 


\section{Refugee Students' Experiences in Schools: Social and Academic Adjustment}

When asked to give their impressions of how refugee students adjusted in class many teachers either did not or could not distinguish between refugee and immigrant students. The general impression they had of ESL students, whether immigrants or refugees, was that the students were shy, withdrawn, quiet and subdued. However, a few teachers noted that refugee students did stand out in terms of registering in school in the middle of a year; transferring to another school shortly after their enrolment; missing school for days to deal with immigration matters; bearing physical scars from their war-torn homelands; and often looking pale and fatigued. Some of them manifested inexplicable behaviours such as clinging on to objects; but many more seemed overwhelmed by the new school environment, unable to follow classroom routines, or unsure of how to behave or participate in class (e.g. failed to observe class rules or remain seated, and wandered around in the classroom). Teachers realized that these maladaptive classroom behaviours were more common among the ones with little prior schooling, especially for those who had been in refugee camps for years or who originated in poor rural areas where formal schooling was lacking. These students were not familiar with classroom discipline, nor were they used to staying seated indoors for two or three hours. They had a short attention span, and had a hard time following regular school routines or knowing what to do in class. Absenteeism and truancy were not uncommon.

Of course, not all refugee students manifested these traits in school. Many refugee students kept themselves at very low key. More often than not, because of their reticence or low profile, these students remained unnoticed in class, and were often mistakenly assumed to have no special needs other than the need for second language acquisition. But an elementary teacher who had worked for years with students from Vietnam, Sri Lanka and El Salvador noted that if these students' psychosocial needs remained undetected or not properly addressed, their withdrawn or passive behaviours could develop into different modes of aggressiveness in and out of the classroom.

\section{Peer associations}

Most refugee students admitted that they tended to associate with peers from their own ethnic background, with whom they felt more comfortable. On the other hand, regular classroom teachers noticed that local students were not always willing to help, associate or interact with ESL students, especially those who seemed "peculiar" to them. It was thus not surprising that some refugee students talked about their feelings of being alienated, discriminated against or rejected by local students. The majority of elementary school students and a number of secondary school students interviewed reported having encountered racial incidents, ranging from verbal to physical types. The incidents often took place outside the classroom-on the students' way home, or during breaks or lunch in school yards - and were usually provoked by White or Black students as a group, and sometimes also by their own national groups who had been here longer. For many of these newcomers, their reactions were mostly passive avoidance. They were afraid to complain to teachers or other school staff for fear of retaliation; a few students mentioned that they were even reluctant to tell their parents, especially single mothers, whom they feared could not cope with the knowledge that their child was being victimized.

\section{Relationship with teachers}

Refugee students found ESL teachers more approachable, more caring and helpful, and more interested in their cultures, traditions and past than regular classroom teachers. They reported that it was harder to communicate with, follow ("they speak too fast and never repeat"), or approach the regular classroom/subject teachers. Some found their regular classroom teachers distant, indifferent, reserved, and uninterested. Aside from their teachers, a few students and parents complained about office staff in some secondary schools as being unfriendly, unwelcoming and sometimes hostile to minority students or parents. While it is not unlikely that these students were oversensitive to their teachers' or staff's attitudes towards them, their perceptions point to the need for increased sensitivity and empathy among school staff towards these students' feelings and the unique circumstances they had been going through.

\section{School-grade placement}

In the Toronto school system newcomers are usually enrolled in a grade according to their reported age. Since following school routines itself was already a problem for many of the refugee students; coping with the academic level of other students of their age was even a greater challenge. A few parents or guardians indeed expressed their wish that the school would either allow their children to remain in a lower grade, or offer special programs to help their children establish the foundation for education. On the other hand, some secondaryschool refugee students complained that they were being held back by having to repeat grade(s) or courses which they had already taken in their home country. These expressed concerns point to the need for the school system and individual schools to develop more holistic assessment and placement procedures for refugee students, whose educational backgrounds were often less predictable and more fragmented than those of other immigrant students.

\section{Program level, post-secondary school plans and aspirations}

While about three-quarters of the Canadian-born as well as immigrant students were enrolled in Advanced Level programs, less than two-thirds $(63 \%)$ of the refugee students were in 
these programs. Except for Iranians $(82 \%)$, the proportion of various refugee groups enrolled in Advanced Level courses was lower than the general population $(75 \%)$. Indeed, those from Central America, the majority of whom were from El Salvador, had less than half $(46 \%)$ of their students enrolled in Advanced Level programs.

Among refugee students who intended to go on to university, almost 20 percent were enrolled in a stream (General or Basic program) that would not lead to their goals, as compared to only seven percent of other immigrant students and five percent of Canadianborn students. The mismatch between aspirations and program enrolment, and misinformation about the system was most salient among those from Central America (40\%), Somalia ( $32 \%)$, and Ethiopia (21\%), followed by those from China (20\%), Sri Lanka (18\%), and Vietnam (15\%).

Figure 1: Students' aspirations and program placement by students' residency status

The incongruence between post-secondary school plans and program enrolment among such a high proportion of refugee students indicates their high degree of unfamiliarity with the school system. As noted by the guidance counsellors, extra time is needed to explain to these students "how they fit into the system, and what their next steps should or might be."

\section{English as a Second Language (ESL) Program and Classroom Challenges}

For most refugee students, ESL classes were crucial in serving their language needs at least in the early period following their arrival. But more importantly, such settings played an instrumental role in addressing the psychological needs of these students during their initial school adjustment stage. At this stage, many had the social and emotional need to be with their own group of students, where they could feel more comfortable with others who shared their backgrounds and/or difficulties. However, the in- terviewed students reported that they did not want to be isolated or labelled as second-class. They were eager to integrate into regular programs where there were more students, a wider variety of subjects offered and more opportunities to learn different things. Still the dilemma was that many of these students did feel stressed and overwhelmed in the regular class which seemed to be mainly due to the following obstacles:

- First and foremost was their limited ability in English, which affected their school performance in terms of understanding teacher instruction, class participation, doing inclass assignments, and coping with regular subjects.

- The language barrier could also pose a psychological barrier discouraging students from participating openly and freely in class. Many refugee students said that they wanted to speak up as other students did, but they were often overcome by apprehension, shyness and embarrassment caused by their communication difficulties

- This psychological obstacle of course could either be reduced or exacerbated by the attitude of the teacher and other students. Some students said that they were frustrated and felt uneasy, put down, or depressed because they sensed that their teachers or other students did not have the patience to listen to them, or to understand their questions when they could not express themselves fluently.

- Another factor underlying these

students' inhibition in class was

Table 1: Part-time Work of Different Refugee Groups

\begin{tabular}{lccc}
\hline $\begin{array}{l}\text { Refugee Students } \\
\text { Origin }\end{array}$ & \% who worked & $\begin{array}{c}\text { \% who worked 16 hrs. } \\
\text { or more per week }\end{array}$ & $\begin{array}{c}\text { Averaage hrs. } \\
\text { worked per week }\end{array}$ \\
\hline China & 37 & 46 & 16 \\
Sri Lanka & 24 & 53 & 18 \\
Vietnam & 23 & 43 & 15 \\
Iran & 27 & 38 & 14 \\
Ethiopia & 39 & 71 & 20 \\
Somalia & 24 & 62 & 19 \\
Central Am. & 22 & 65 & 20 \\
\hline
\end{tabular}

their previous school system and home culture. Many students from countries like Sri Lanka, China and Ethiopia had such high respect for or even fear of teachers that they were hesitant to approach them for questions. Coming from school systems that were teacher-centered, where teachers were the holders of knowledge and students were the recipients, these students were not used to expressing their opinions openly in class. Instead of becoming active learners, the students attended their class quietly, turned to their friends for assistance, or tried to guess or find out answers on their own. This accounted in part for their low profile and withdrawn image. Hence, the fact that these students kept to themselves should not be taken as a sign of complacency; rather it should be understood as an indication that proactive measures need to be taken by the school and teachers.

The four barriers mentioned above may also apply to newly arrived immigrant students. But for refugees, these barriers were further compounded by the wide educational gaps experienced by many school-age children or young adult refugees as a result of frequent interruptions or disruptions in schooling before and during their migration. These students lacked basic learning skills or concepts; they virtually had to start from scratch, and thus had more obstacles to overcome than other students. These problems were exacerbated by the age factor. Those arriving at a younger age would at least have the time to acquire the language and

\section{students' inhibition in class was}


basic learning skills during their formative years. But for those who came as adolescents, academic gaps were more difficult to overcome. Without special interventions to develop their learning skills, these students' educational gaps remained unfilled. Finally, refugee students' post-migration experiences (e.g. frequent relocations, enrolling in schools in the middle of a year) posed further hindrances to their school adjustment and concentration.

\section{Homework}

Probably due to the extra layers of barriers they encountered, refugee students needed much more time to deal with their daily school work than others. Our data reveals that, except for students from Central America, the proportion of students who spent 16 or more hours per week on homework was much higher among refugee students $(34 \%)$ than among regular immigrant students $(21 \%)$ or the Canadian-born (12\%).

It should, however, be noted that while refugee students in general spent more hours on homework, many of them also had to juggle their study time with long hours of part-time work. (See Table 1.)

\section{Academic performance}

Refugee students as a group were more or less at par with other immigrant or Canadian-born students academically, though their at-risk rate was slightly higher ( $30 \%$ versus $25 \%)$. ${ }^{2}$ However, a further disaggregation of the data indicates that certain refugee groups lagged far behind and became the most at-risk students in the system. Recently arrived secondary school students from China not only fared better than other refugee groups, but also outperformed the general population in average school marks. The performance pattern of those newcomers from Iran, Vietnam, and Sri Lanka was similar to that of the general population. On the other hand, a large proportion of newcomers from Ethiopia, Somalia and Central America were at a high risk of dropping out of secondary school (between $\mathbf{4 0} \%$ and $50 \%$ chance versus $25 \%$ at the system level).

Tamil parents talked about how their children were keen on study, and liked their school subjects; some had been identified as gifted or awarded for their essay writing, and also most found mathematic easy and did very well in it. On the other hand, the majority of secondary-school Latino students interviewed indicated that they were not doing well at school or had learning difficulties. Some even mentioned that they felt like giving up many times. While further research is necessary to explain the performance differences among the different subgroups, as discussed earlier, part of the variance could be attributable to the students' previous schooling, their premigration situations, the length and nature of their migration process, and their post-migration experiences.

\section{Parental and family support}

There was a general view among school staff that refugee parents were not sufficiently involved in their children's education, and that they were hard to reach. It was not uncommon to find a very low participation rate among refugee parents in school meetings, school functions and activities, or sometimes even teacher-parent conferences or interviews. Refugee parents' inability to link with the school system should, however, not be interpreted as a general lack of interest in their children's education. Because of their language difficulties, their cultural perception of the school role, their preoccupations with the intense process of adaptation and adjustment to the new country (including long work hours), and their unwillingness to approach or contact public authorities due to precarious immigration status. These parents were often confused about the role expected of them by the school, and how they could assist their children's education. Hence, it would notbe effective merely for the students or their families themselves to cope with and adjust to the school system without the active outreach and input from the school itself.

\section{Staff, School and the Board Responses to Refugee Students}

Many regular classroom/subject teachers admitted that they had difficulties in dealing with refugee students and that they did not have a clear idea of who their refugee students were, or how many they had in their class or school. In fact, some of the teachers found it inappropriate to identify individual students' background and history because they believed that it was the student's private or personal matter. Furthermore, they did not see any pedagogic reasons for "labelling" or identifying students' immigration status and background. For them, all students should be treated the same way. There were, however, other teachers who made deliberate attempts to understand the individual refugee student's background through one-on-one conversations, class discussions or journal writing. They found it important to know what refugee students had gone through because they reckoned that the experiences and needs of these students were unique and serious enough to require staff attention and interventions. These teachers supplemented regular oral instruction with written instructions, demonstrations, visual illustrations, or special tutoring. New ESL students were teamed or paired with other students who had been here longer and spoke the new students' language. Some teachers turned to bilingual staff to help them, and, more importantly, link them with students' families whom they found difficult to reach-for example, interpreting during parent interviews, calling parents to return school forms, and making home visits. A handful of teachers took a step further by asking refugee students to write about their home countries and traditions as part of the class work. A few subject teachers had even tried to integrate these students' cultural background and experiences into part of the classroom learning activities-e.g. through journals, class discussion, building a "community spirit" among Canadian and non- 
Canadian students - in order to make students feel free to support or to confide in one another.

ESL teachers were more knowledgeable about the situation and needs of refugee students. While addressing their language needs was the primary service of ESL staff, many ESL teachers found themselves counselling these students, referring them to different sources for help, or even providing them with assistance out of school. They sat on the local school teams bringing forward these students' names for discussion and were also actively involved in co-ordinating special programs such as setting up dropin centres, organizing field trips, and developing buddy systems for newly arrived immigrant and refugee students. Despite these efforts, ESL teachers did regard themselves as not knowledgeable enough or qualified to counsel students. Furthermore they felt their programming for refugee students was restrained by the limited resources available, and by the little control they had over their own programs.

Aside from teachers, certain student support staff groups in the Toronto Board had also provided direct services to newly arrived students. Guidance counsellors offered students one-on-one counselling and special information sessions or orientation programs on such topics as the Ontario school system, secondary school courses and programs, post-secondary education requirements, and sometimes even the Canadian immigration process. While most of these activities were meant for a larger audience, immigrant and particularly refugee students seemed to be the group to have benefited most.

Social workers-especially those who were multicultural/multilingual-were the most frequently referred to group. Indeed, school staff expressed the need for more access to multilingual services, and would like to see an improvement in the deployment and availability of bilingual social work staff, especially for certain language groups such as Tamil, So- mali, Ethiopian, and Vietnamese. In a few schools, bilingual social workers were sometimes invited to conduct information sessions either for refugee students or school staff (during professional development days or at staff meetings).

The intake/welcome workers of the Board's two Welcoming/Reception Centres-Greenwood and Bickfordoffered reception, counselling/referral, assessment and placement services usually in the clients' own language. About two-thirds of their clients were refugees referred by welfare agencies and community service agencies. Their clients, mostly adults with families, requested placement in the schools for their children as well as for themselves, as they generally could not find jobs. According to the welcome workers, "students who come to the Reception Centres first and are then placed in schools seem to adjust better, knowing there is someone there who speaks their language, and return to the Centre for support."

Despite the different nature and degree of involvement of various teaching and school support staff, most agreed that they were not ready or equipped to meet refugee student needs due to the difficulties they had in terms of:

- identifying refugee students,

- the general lack of information and training about refugee students,

- limited resources, including limited access to bilingual staff, and

- reaching parents and involving them in their children's schooling process.

\section{Overall School Responses}

At the time of the research, the issue of refugee students was not yet articulated or defined at the school level and even when individual refugee students happened to be discussed at team meetings, their refugee status virtually never entered into the discussion. Nonetheless, some of the sampled schools did initiate, aside from the existing ESL or after-school heritage language programs, special services for ESL students. Although none of these initiatives were specifically designed for refugee students, they seemed to work for them.

In some schools, refugee students were placed in a reception class for a short period of time before enrolling in regular and/or ESL programs. Other schools had students attend a reception program for half a day and their regular grade in the afternoon. The reception programs were designed to provide a small class/group setting (10-15 students), where new students could get initial orientation and introduction to their schools, basic English, or even life skills.

An integrated international language class was used at one school as part of the reception for the newly-arrived from the refugee hostels. The students were placed in the heritage programs full-time for a week or two for initial support in the first language before transferring to a reception class, and finally to a regular class.

Examples of other local school efforts include permitting students to read/write in their own language in class if necessary; having first language tutors in class; team teaching between regular teachers and ESL teachers; forming an "Ambassador Club" in which student peers became buddies to newcomers; and scheduling periodical "Reception Afternoons" for newly arrived families and members of the school staff.

\section{System Responses}

The Board's reports on ESL programs and services and on youth alienation have identified the needs of refugee students as one of the important areas that need to be addressed. The establishment of two Welcoming/Reception Centres in the late 1980 s and early 1990 s by the Board has been one of the most significant services offered by the system to new refugee and immigrant families. Another system effort was the partnership with the federal government and local community agencies in delivering language classes for the last few years to thousands of adult immigrant and refugee students in the city. Other smaller-scale efforts included 
compiling an informal resource list of support staff for schools with refugee students, and offering occasional workshops for interested staff on refugee students.

\section{Suggestions for Assisting Refugee}

\section{Students}

This study has garnered a myriad of practices and suggestions from different interest groups as to how the Board, individual schools and teachers can assist their newly arrived refugee students. The study suggests that a real effort to assist these students has to involve actions at both the school and the system levels and that perhaps a mechanism is necessary to ensure that the Board policies, programs and concerns for refugee students are effectively translated to the school and classroom level.

At the school level, a whole-school approach was proposed. Rather than relying on the efforts of individual school staff, schools need to deal with the situation as a school issue. In other words, all staff, including the international language instructors and school community advisors should be involved in a co-ordinated manner. This approach has eight components:

1. referring newly arrived refugee students and families to the Board's Reception/Welcoming Centres for obtaining proper welcoming reception, preliminary assessment, placement and initial assistance;

2. providing school-based reception to newly arrived students by giving them a warm welcome by the staff and students, and by offering special orientation programs to familiarize themselves with the new environment and the school routines;

3. conducting thorough assessment of refugee students' academic and social needs with appropriate resources and with the assistance of trained multilingual staff;

4. offering first language support by developing a first language buddy or mentoring system, and by giving instructional assistance in their own language during the transition period;

5. promoting an inclusive learning environment and curriculum for all students in order to make new students feel welcome and to allow other students a better understanding of the newcomers' needs and circumstances;

6. co-ordinating and promoting health, education and social services for refugee students in schools;

7. offering programs to familiarize new refugee parents with the educational system, and to encourage parents' active involvement in school and their children's education; and

8. supporting school staff by informing them about the needs of different groups of newcomers, and by facilitating interdepartmental communication and rapport in order to ensure concerted effort in meeting the needs of refugee students.

To facilitate the school efforts, the Board can offer important support in the following areas:

- compiling and disseminating currently available information regarding refugee students-i.e. research findings such as the present study, statistics on refugee students, resources materials for school staff, and information kits for refugee students and families;

- offering in-service and/or preservice for school and education office staff and other related personnel in order to sensitize the staff to the issue, and to offer them appropriate strategies to address the academic, social and emotional needs of refugee students;

- continuing and expanding the existing ESL programs;

- improving the deployment and availability of bilingual support staff;

- offering specific expanded opportunities programs for students who are not meeting the grade expectations; and

- assisting in evaluating school initiatives and acknowledging effec- tive practices for other schools to consider.

- supporting Anti-racist Education, Conflict Resolution and Anti- bullying projects.

Finally, it should be reminded that it is important to tap into resources and services of various community organizations and mental health agencies in order to address the social and emotional needs of their refugee students. Last but not the least, it is crucial to maintain dialogues with both the provincial and federal governments about the critical need for funding and support of programs for immigrant and refugee students.

\section{Notes}

1. These were estimates based on the Toronto School Board's on-line student registration records. It should, however, be noted that the registration records themselves did not collect information on students' legal status. These students were identified indirectly with the use of two criteria: students' countries of origin and their recency of arrival in Canada. Therefore, students coming from one of the major refugee producing countries within the past four years during the time of data collection were extracted from the on-line registration records. A sample of these identified students were contacted individually for verification.

2. The seven language groups included those from Sri Lanka, China, Vietnam, Iran, Afghanistan, Central America, Ethiopia, and Somalia.

3. It should be noted that this overall at-risk rate for refugee students may be an underestimate, as it only captures those refugee students who enrolled in school at the beginning of the school year as other students. Those who enrolled later in the year, as happened more often among refugees than other students, were not reflected in the figure. An internal study by the Research Department of the Board notes some preliminary indications that students who enrolled later in a school year were more likely to be at risk than those who started their school year in September. $\square$ 